\title{
Challenges in treating earthen construction materials as unsaturated soils
}

\author{
Charles E. Augarde ${ }^{1, a}$, Christopher T.S. Beckett ${ }^{2}$, Jonathan C. Smith ${ }^{3}$, and Andrew J. Corbin ${ }^{1}$ \\ ${ }^{1}$ School of Engineering and Computing Sciences, Durham University, Durham, UK \\ ${ }^{2}$ Civil, Environmental and Mining Engineering, University of Western Australia, Australia \\ ${ }^{3}$ Cundall, Regent Centre, Newcastle upon Tyne, UK
}

\begin{abstract}
Earthen construction is a loosely defined term covering both the materials and methods for creating structural components from mixtures of subsoil, often with the addition of chemical or mechanical stabilisers. There is evidence of Man creating earthen structures for thousands of years, and there are many world heritage sites containing earthen structures, some of which present issues in terms of conservation. In some parts of the world there is a growing market for new-build earthen structures and a key issue here is the lack of design codes. Since these materials are composed mainly of particulates and water it is natural to regard them as geotechnical in nature, where friction and the presence of water have a key influence on material properties, however until very recently this was not the case, with earthen construction materials regarded as weak concrete or masonry. In this paper we examine these opposing views and discuss the issues associated with regarding these materials as unsaturated soils. The paper is illustrated with outcomes from research at Durham University carried out over the past ten years.
\end{abstract}

\section{Introduction}

Earthen construction, meaning the construction of structural components (walls, arches, domes and lintels) from subsoil, is receiving increased interest, despite it being something Man has done for thousands of years, and the oft-repeated "fact" that one third of the world's population live in structures at least partially made of "earth". Interest in the developed world is being driven by the potential green credentials of these materials, i.e. low embodied energy as compared to fired masonry or concrete blockwork, and heat/humidity buffering which could reduce in-life energy costs. There are also drivers associated with the preservation of heritage structures made of soil, of which there are many famous examples [1]. Specific techniques of earthen construction are unitbased (e.g. Adobe, compressed earth blocks) and insitu (rammed earth, Cob). In all cases the base materials are selected mixtures of gravel, sand and clay, to which stabilisers (chemical or mechanical) are sometimes added (e.g. cement or fibres respectively) $[1,2,3]$.

If the interest in earthen construction (EC from here) is to lead to environmental benefits, it is clear that the specification, design and construction using these materials will have to change. At present, EC is seen as a niche building option in Europe, beloved by architects but neither widely available nor cheap. In Western Australia, Canada and California, however, there are mature EC markets for small to medium-size buildings, due in part to the climates of these places, but also because of the activity of local contractors and consultants, notably David Easton in California, Meror Krayenhoff in Canada and Steven Dobson in Australia, who came together (with the first three authors of this paper) at the First International Conference on Rammed Earth Construction in 2015 in Perth, Australia [4]. However, even in the countries where there is measurable activity, expansion of the market is prevented by the virtual absence of design codes, unlike the situation for steel, concrete, masonry and timber which all have their own well-established codes, certainly in the developed world. In contrast, much earthen construction is designed either from a craft point of view or, if engineering is involved, the material is assumed to be homogeneous, continuous and much like a weak concrete or masonry.

While some consider that the lack of design codes stems in part from the concrete and masonry industries, perceiving a threat to their products, the absence is mainly due to a lack of quality, rigorous scientific investigation and the fact that, until 5-10 years ago, it was led by structural engineers who ignored both the particulate nature of, and the importance of water to, these materials, both of which are regarded as key in our understanding of geotechnical materials. It is for this reason that this paper is in this conference, because better understanding of the behaviour of EC materials may be achieved by regarding them as manufactured unsaturated soils. To explore this idea we consider the various ways that EC materials are viewed and survey the relatively few existing links to other areas of geotechnical research, highlighting some challenges; challenges which should be regarded not as barriers but the starting point for future research.

\footnotetext{
a Corresponding author: charles.augarde@dur.ac.uk
} 


\section{The two views of earthen construction materials}

Specific guidance for the design and construction of structural components using various EC materials can be found in the landmark book by Houben and Guillard [2] and the more recent UK publication by Walker et al. [3]. Only New Zealand has anything approaching a Eurocode for earthen construction. What characterises all these sources of guidance is the structural engineering approach taken to the material, with very little acknowledgement of the particulate nature of the source materials, and the effect of water. Strength is not predicted using a scientific approach; rather, rules often rely on previous experience with similar materials. Structural members are sized in a similar way to the approach used with masonry in Europe, and it is the structure that is designed, e.g. effective lengths and slendernesses are checked rather than states of stress at material points. The structural approach is also evident in the small research literature on EC materials. Most testing reported on EC materials is closely related to concrete testing, e.g. unconfined compression, fracture tests [5] and insitu testing of structural components [6]

An alternative is to regard EC materials as unsaturated soils, where suction plays a major role in shear strength, but where one is studying a structural component rather than a body of soil. It appears that the first publication to make the link, between suction and the strength of earthen construction materials, is the 2007 conference paper of Gelard et al. [7], which came at the same time as the group at Durham was carrying out the experimental tests which later appeared in [8]. The latter tests were constant water content, unconfined compression tests on unstabilised rammed earth samples where the suctions were measured during testing using high capacity tensiometers (developed by Toll and coworkers). A clear link was shown in [8] between suction and shear strength, although at much lower suctions than usually experienced with EC materials in the field after drying. Later work, making use of filter paper measurements of much higher suctions, served to confirm this approach (e.g. the results shown in Fig. 1 from [9]). Recently, Gallipoli et al. [10] also put forward the case for a geotechnical approach to these materials.

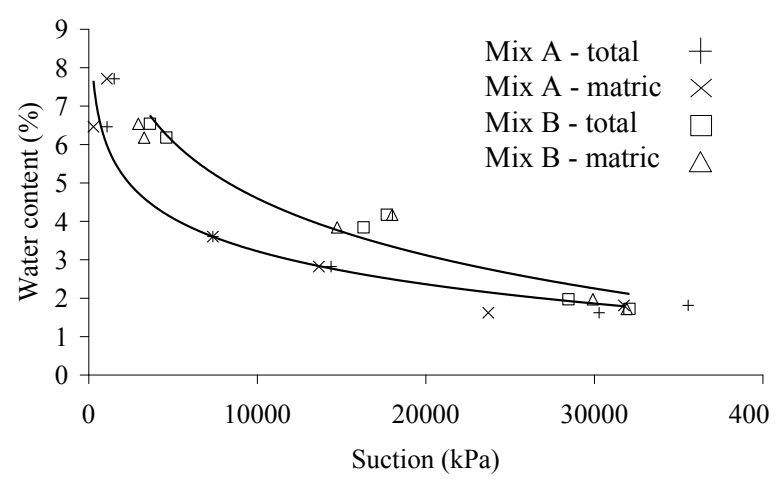

Figure 1: Water retention curves for various samples of rammed earth at varying drying levels (from [9]).

\section{The challenges}

On the face of it, it sounds entirely reasonable to adopt the geotechnical approach described above, however there are a number of challenges to be addressed and our assessment is that in fact a mixture of the two approaches (geotechnical and structural) is necessary. While there are some parallels with current geotechnical research which might be extended to EC materials, these are often inappropriate.

Taking rammed earth as an example, we can define this material in the following way: cross-anisotropic (due to the means of production), very low degree of saturation, high dry density, brittle, possibly containing chemical bonding or reinforcement and having a very large particle size distribution (clay, sand and gravel). In use the material is placed so that a large surface area is subjected to wetting and drying, a very different situation as compared to standard "buried" geotechnics.

\subsection{Constitutive modelling}

The development of constitutive models is one of the main activities undertaken by the geotechnical research community, and this is particularly the case in unsaturated soils. It is worth considering why constitutive models are needed. For instance, a large body of work in unsaturated soils has been aimed at understanding and predicting the long term behaviour of nuclear waste containment systems including bentonite. Primarily the interest is hydraulic, i.e. will leakage occur? Considering EC materials, strength and durability are the main concerns, rather than movements and permeability so one might question if a full-functioning constitutive model is actually needed for EC materials.

A common reason for developing a constitutive model is for use in numerical modelling using finite elements and there have been some moves in this direction by researchers in EC materials. Nowamooz \& Chazallon [11] developed a finite element model of a rammed earth wall using a non-linear elastic - perfectly plastic model with a Drucker-Prager yield criterion. The effect of suction was included assuming a linear increase in tensile strength similar to the Barcelona Basic Model. More recently Gerard et al. [12] presented results from tests on an unsaturated Belgian clayey silt with similar properties to a typical RE mix (without a gravel fraction), results of which were then used to validate a constitutive model based on a generalized effective stress (Bishop stress) approach with values suggested for the effective stress parameter $\chi$. The attempt to fit an EC material into one of the two established methods for dealing with effective stress in unsaturated soils is an interesting development, also seen in [13].

Other, perhaps more satisfying possibilities for a constitutive modelling framework for EC materials are those proposed for compacted unsaturated soils, compaction being a key ingredient in the production of many EC materials. In these models it is recognised that microstructural changes (i.e. void and particle size distribution) should be taken into account. In particular, 
many geotechnical studies have shown that compacted clay forms aggregated structures which behave like large particles inside which water is trapped, being separate to water held in the pendular regime between the particles (both aggregates and larger solid particles). A recent example of such a modelling framework can be found in [14] in which the microstructure is quantified by the ratio of microvoids (i.e. voids within the clay aggregates) to total void ratio, a state parameter on which the stress and suction behaviour can be based. Another possible starting point is the work of Koliji [15]. These particular models (as are many others for compacted soils in geotechnics) are developed for clays and silty-clays and therefore consideration would be needed to extend this to EC materials which contain a much wider particle size range. In addition, the gap grading inherent in EC materials due to manufacture is a feature unlikely to be present to such a marked degree in the natural soils routinely tested in geotechnics.

A much greater challenge is to consider how to extend these models to accommodate the very brittle behaviour and fracture common in EC materials. Fracture mechanics here (as for other materials) is concerned with fracture initiation and propagation and, of the little scientific work published on this, most have adopted linear elastic fracture mechanics principles as a start (e.g. the work presented in Brune et al. [16] on Roman mortars). It is here that it seems necessary to work with tests established for rocks and bonded materials such as concrete, and to investigate the constitutive models used for these materials. Continuum elasto-plasticity deals poorly with discontinuities whether they are fractures or shear bands (to cite one other area of geotechnics).

Some ideas on appropriate tests for fracture testing for EC materials are explored in [17] in which the development and use of a wedge splitting device for earthen construction materials is described and demonstrated. Fig. 2 shows the device and Fig. 3 shows an example of a fractured stabilised RE specimen obtained with this rig. With this device one can obtain reliable and repeatable fracture energies for these materials, data which can inform a constitutive model for fracture. Adopting tests like this is pragmatic, similar to the use of Brazilian tests for tensile strengths.

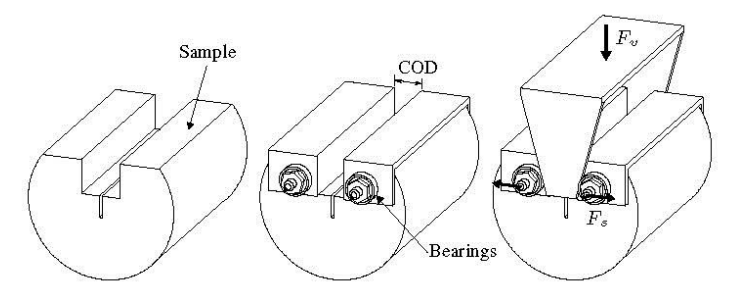

Figure 2: Wedge splitting device for obtaining the fracture energy of earthen construction materials (from [17]).

However, it seems unlikely that a single, holistic constitutive model can be developed to bridge the gap from low-suction to very brittle behaviour and thus be able to model the full range of wetting and drying cycles likely to be experienced by EC materials in the field. As with other engineering problems in which fracture has to be introduced, it may be necessary to change the numerical modelling paradigm to allow discontinuity, e.g. to use XFEM, and there is recent work of just this nature with EC materials in mind [18].

\subsection{Investigating the microstructure}

As indicated above, it is clear that microstructure is important in determining the mechanical and hydraulic properties of unsaturated soils and this must also be the case with EC materials. Microstructural investigations of soils have traditionally used mercury intrusion porosimetry (MIP) to determine void size distributions (or rather pore entry diameters which are something different), and more recently x-ray computed tomography (XRCT) has appeared to have become mature enough to become useful to geotechnical engineers.

A $\mathrm{PhD}$ thesis [19] recently completed at Durham contains a new body of research assessing the various means of investigating the microstructures of EC materials (rammed earth in particular) with an emphasis on XRCT. In [19], as a precursor to the use of XRCT on EC materials, a study is presented to assess the way that XRCT has been used to date in geotechnics, where three key journals (Géotechnique, Géotechnique Letters and Granular Matter), and two recent conference proceedings were surveyed (UNSAT2014 and IS-Cambridge 2014). A total of 40 papers were found this way and from each the following information was obtained (where provided):

- material analysed;

- sample size;

- $\quad$ voxel size, or resolution;

- XRCT scan descriptions;

- results presented.

There is insufficient space here to cite all the articles consulted (full details are in [19]) however some overall statistics are presented which are of interest. Thirty papers provide information regarding the material scanned (Figure 4a shows the range of particle sizes). It is clear that the majority study particle sizes (actually object sizes) between $0.1 \mathrm{~mm}$ and $2 \mathrm{~mm}$, i.e. sands. This is clearly at odds with many natural soils and certainly with all EC materials. Twenty-seven papers provide

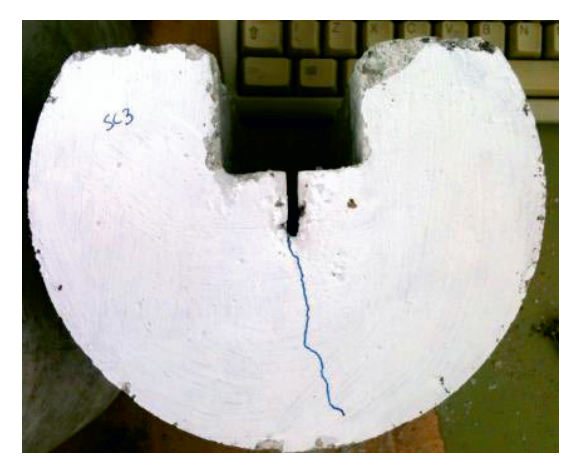

Figure 3: An example of a fractured stabilised RE specimen using the fracture in [17]. 
information regarding the size and shape of the (cylindrical) samples scanned. Five of these investigations took smaller cores from larger samples on which other laboratory experiments had already been performed. Figure $4 \mathrm{~b}$ shows the diameter of the samples scanned in each of these 27 papers from which it can be seen that a large proportion of investigations only scanned small samples $(<12 \mathrm{~mm})$ whilst a significant minority, 5 investigations, performed scans on much larger (e.g. oedometer size) samples. It was surprising to find that the $38 \mathrm{~mm}$ diameter triaxial cylinder was only used in a single surveyed publication when one might expect XRCT to be a useful tool in tandem with standard triaxial tests. While no discussion of the choices of sample size can be found in any of the papers surveyed it is presumed that the XRCT machines performing the scans required small sample sizes to obtain the required resolution, or to fit within the scanning chamber. This survey is, of course, by no means the full picture of XRCT use in geotechnics but the trends are clear; the soils scanned tend to be those which will "scan well" and there are questions about the viability of current XRCT scanners for investigation of soils with varying particle sizes.

There is a conflict in XRCT scanning between wishing to obtain the highest resolution and the largest area of coverage. One can rarely achieve both, and with a compacted material with a range of particle sizes (e.g. a rammed earth mix) one cannot see right "down to the clay". Instead a pragmatic approach must be adopted where sample size is chosen to balance the capabilities of the XRCT machine and the desire for representative samples. A very small sample will scan well but is unrepresentative of a mix where there could be large sand and gravel particles present, which is the case with EC materials such as rammed earth.

It would appear then that microstructures of EC materials require a two-stage process of investigation: MIP to determine the microstructure up to the micron level of the clay aggregates, and XRCT above that. There are clear challenges in sampling for the former (i.e. how representative of the clay aggregates in a large same of an EC material is a given sample of a size suitable for MIP). It could be that the microstructure at the sand/gravel level is not significant and the main source of strength lies in the clay aggregates, however this remains speculation without further experimental work.

\subsection{Additives and materials}

EC materials can contain both chemical and mechanical additives, e.g. cement and fibres respectively. Clay soils have long been stabilised by the addition of lime or cement and there is a mature research literature on this topic, examples including the many papers by Consoli and co-workers (e.g. [20]) where, interestingly, extensive
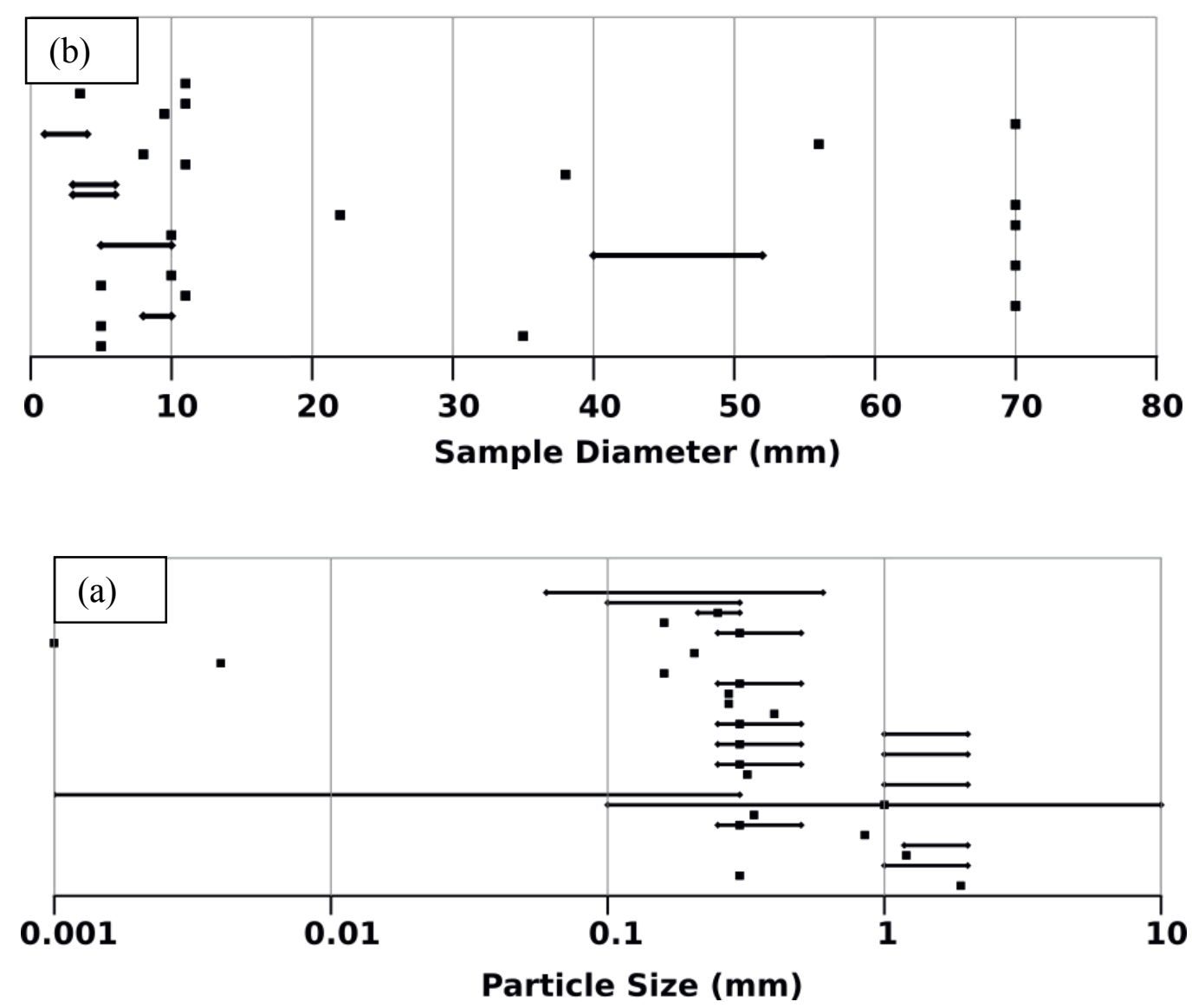

Figure 4: Results from the literature survey on XRCT use in geotechnics 
use is made of unconfined compression and Brazilian tests, as found in the "structural" literature on EC materials. Constitutive models have also been developed for these materials, e.g. [21]. Modern stabilised rammed earth contains between $1 \%$ and $15 \%$ cement by mass so at the higher end the contribution to strength from cementation will dwarf anything from suction and the material could be regarded as a weak concrete. At the lower end, findings for cement stabilised clays may have some applicability but the addition of compaction in the case of the EC materials may make it inappropriate. Contractors, particularly in Australia, seem to have concerns that the presence of clay in their rammed earth mixes will inhibit the cement hydration, and this tends to lead to a choice of mix with very low levels of clay.

There is also a widespread belief in the EC building community that the type of clay is of prime importance, i.e. an avoidance of any expansive materials. This can further reduce the environmental benefit as clays may have to be imported rather than being won locally. In fact, recent studies have shown that there is negligible deterioration in the properties of rammed earth mixes which contain up to $20 \%$ of their clay fraction as expansive. Figure 5 shows results of filter paper tests on

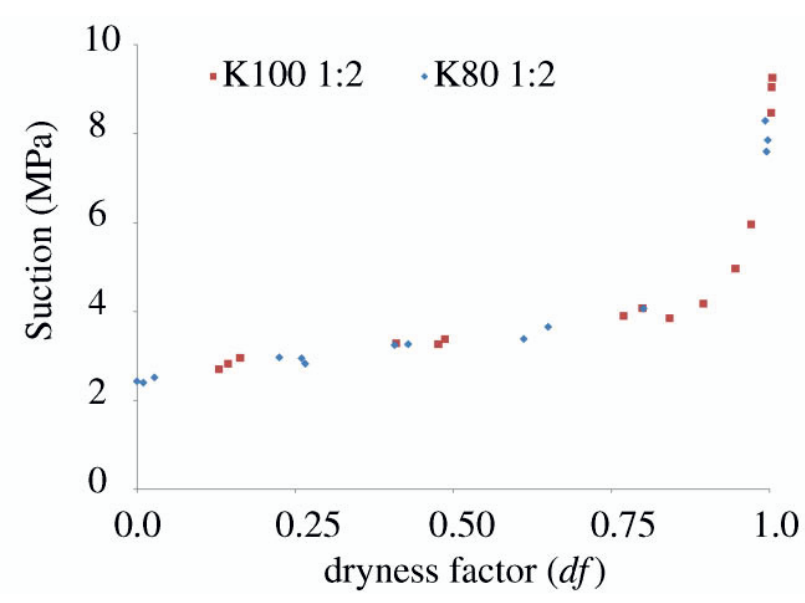

Figure 5: Results for filter paper tests on sand/clay mixtures. K100 is pure kaolin. K80 is $80 \%$ kaolin/20\% bentonite [22].

two samples of a clay-sand mix (in proportion 1:2, similar to a rammed earth mix without gravel) in which one has a clay fraction entirely composed of kaolin and the other has a clay mix of $80 \%$ kaolin and $20 \%$ bentonite. The plot may be unusual to geotechnical engineers as suction is plotted against "dryness factor", $d f$ which is a measure of the ratio of the water content at optimum (at the point of compaction), $d f=0$ and final equilibrated dry state after a number of days, $d f=1$. The two materials follow a similar path and other mechanical tests also show similar agreement [22]. This is an indication that for these mixed soil materials the expansive clay behaviour is inhibited in some way.

Fracture inhibition in brittle materials usually means reinforcement in tension, and fibre-reinforcement is a key feature of many earthen construction materials, e.g. the straw in adobe bricks and cob is a form of tensile

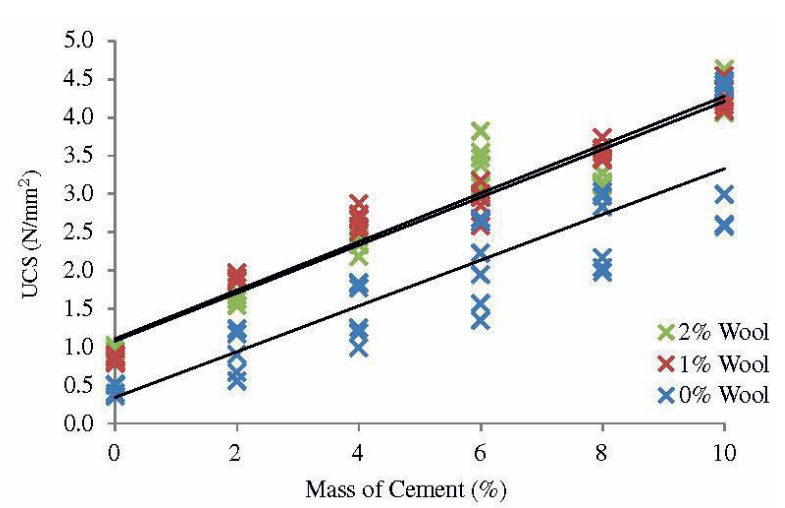

Figure 6: UCS results for stabilised rammed earth samples with varying amounts of cement stabiliser and wool fibre reinforcement [17].

reinforcement. It is an intriguing question to consider what role these fibres play in terms of water storage and distribution, and the nature of the bond between the fibres and the surrounding material. A recent review of the use of fibres in EC materials can be found in [23].

Investigations have been carried out at Durham on the properties of fibre-reinforced mixes at the macro scale and also the fibre/earth bond itself. Corbin \& Augarde [17] demonstrated the major change in fracture behaviour between un-reinforced and reinforced stabilised RE and also the increase in unconfined compressive strength (UCS) with wool reinforcement (an example plot is given in Fig. 6). Investigations of the fibre-EC material bond behaviour are presented in [24] including the development of a new test rig to carry out pull out tests on samples of earthen materials. In this study pull-out loads were measured using a jute fibre embedded in both stabilised and unstabilised rammed earth mixes. Water content, fibre embedment length and dry density were all varied. Two example results plots are presented here in Figs. 7 and 8 .

In Fig. 7, peak pull-out forces are plotted for a large number of tests where interface failure (i.e. loss of bond between fibre and soil) occurred. The majority of results follow a trend of major increases in pull-out force for the lowest water contents and less marked differences for higher water contents. The link between water content and strength might be seen as counterintuitive when one considers shrinkage would be greater the drier the soil gets, and hence one might conclude the interface strength should decrease as soil shrinks away from the main fibre axis. While this might be the case, other studies [17] suggest that the main bonding occurs between the soil and "microfibres" extending outwards from the main fibre axis, rather than the main fibre axis alone, and these bonds could be less influenced by shrinkage.

Also clear from Fig. 8, and in many of the results in [24], is the presence of peak and residual strengths, potentially unsafe for design when the materials are unstabilised. This behaviour is thought to be associated with dilation of the soil increasing bond strength initially, followed by frictional failure. What is also clear is that some stabilisers serve to add ductility (cement) while others make the material less robust (lime). Clearly, single fibre studies have to be scaled up to the macro- 
material case but these findings are interesting for revealing mechanisms of failure. The behaviour of fibrereinforced soil has of course been studied by the geotechnical engineering community for a number of years (e.g. $[25,26])$ however these studies are usually for natural soils at much lower compaction levels and higher saturations than the conditions found in earthen construction.

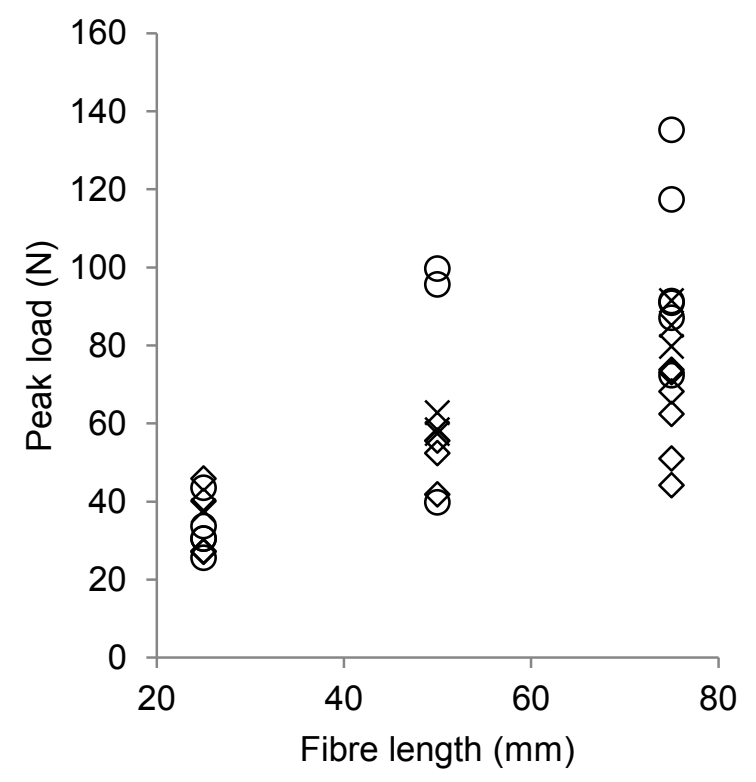

Figure 7: Results from pull-out tests of fibres embedded in rammed earth samples. Peak loads are shown for varying water contents: $3 \%$ wc (circles), 7\% wc (crosses), $11 \%$ wc (diamonds) [24].

\section{The future}

This paper has outlined links to existing research in geotechnics and also identified gaps which need to be filled if we are to develop a scientific understanding of EC materials. With a robust and validated constitutive framework for EC materials, taking aspects of modelling from unsaturated soil mechanics and from brittle bonded material modelling, e.g. for weak concrete, it is likely that design codes could follow.

The ultimate goal of earthen construction material research, from an engineering viewpoint, is to improve material modelling and structural design. However, the earthen construction industry is small and practitioners are generally unfamiliar with geotechnical terminology or analysis concepts. Rather, they will defer to familiar procedures and materials to reduce risk. The most significant challenge facing the treatment of earthen construction materials as unsaturated soils is the power and familiarity of existing, simple empirical techniques and the need to convince industry (and researchers) of the benefits that can be achieved by adopting new practices.

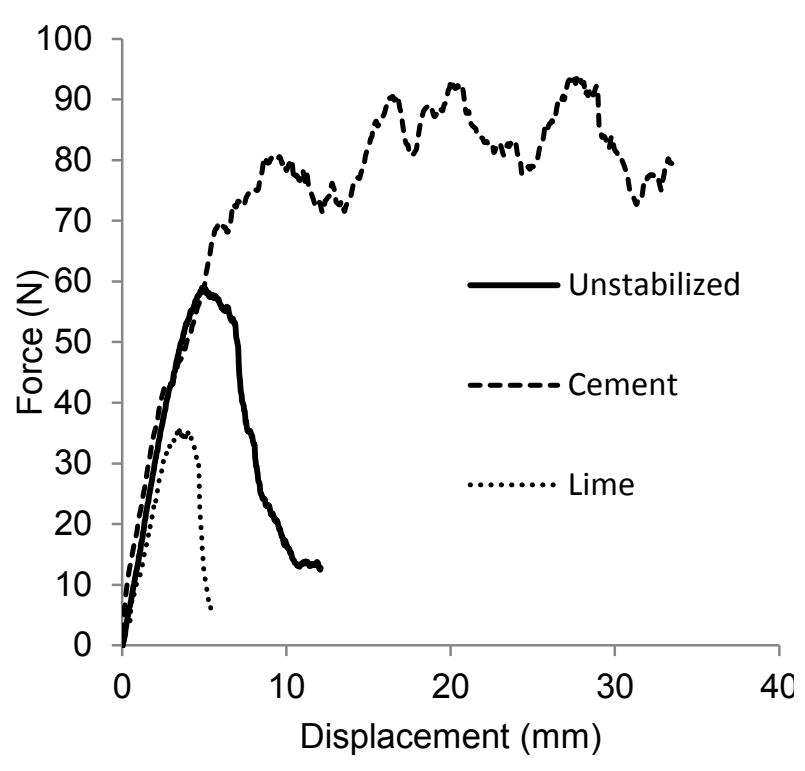

Figure 8: Results from pull-out tests of fibres embedded in rammed earth samples. Force/displacement results for $50 \mathrm{~mm}$ fibres with and without stabilisers (9\%) [24].

Several core unsaturated soil mechanics concepts are already familiar to and indeed at the heart of earthen construction, for example:

- the need to compact material to achieve a high density and sufficient strength;

- the need to correctly identify the right water content to aid compaction;

- the need to control material grading to ensure sufficient compactability;

- the need to limit clay content to reduce shrinkage;

- that material strength increases on drying;

- that materials must breathe to avoid water build-up and possible failure.

To address the challenge of industry uptake, these concepts must be 're-packaged' in an unsaturated soils framework and the ability of that framework to predict their effects demonstrated. For example, Fig. 9 shows the unconfined compressive strengths of two rammed earth soil mixes equilibrated to high and low suction conditions. Soil water retention curves for the two soils are shown in Figure 10, derived from combined filter paper (suctions $<10 \mathrm{MPa}$ ) and vapour pressure results (suctions $>10 \mathrm{MPa}$ ). Material properties are given in Table $1.100 \mathrm{~mm}$ cube specimens were compacted at the optimum water content (OWC) and equilibrated under a range of humidity and temperature conditions using an environmental chamber. Equilibration suctions under given conditions were calculated using the well-known Kelvin equation. Humidities between $30 \%$ and $90 \%$ and temperatures between $15^{\circ} \mathrm{C}$ and $40^{\circ} \mathrm{C}$ were investigated: here, only "high suction" (30\% humidity, $40^{\circ} \mathrm{C}, 168.3$ $\mathrm{MPa}$ suction) and "low suction" $\left(90 \%\right.$ humidity, $15^{\circ} \mathrm{C}$, 14.0 MPa suction) will be discussed. 
Figure 9 shows that strength almost doubled between the high and low suction conditions for both soils. It is unlikely that a practitioner would have the time or the facilities to derive full water retention curves for a given soil, for example Figure 10, or determine a full yield surface for their material, for example as in [12]. However, a change in strength of the magnitude shown in Figure 9 would be critical to a project's feasibility. For example, NZS 4297 (the New Zealand rammed earth

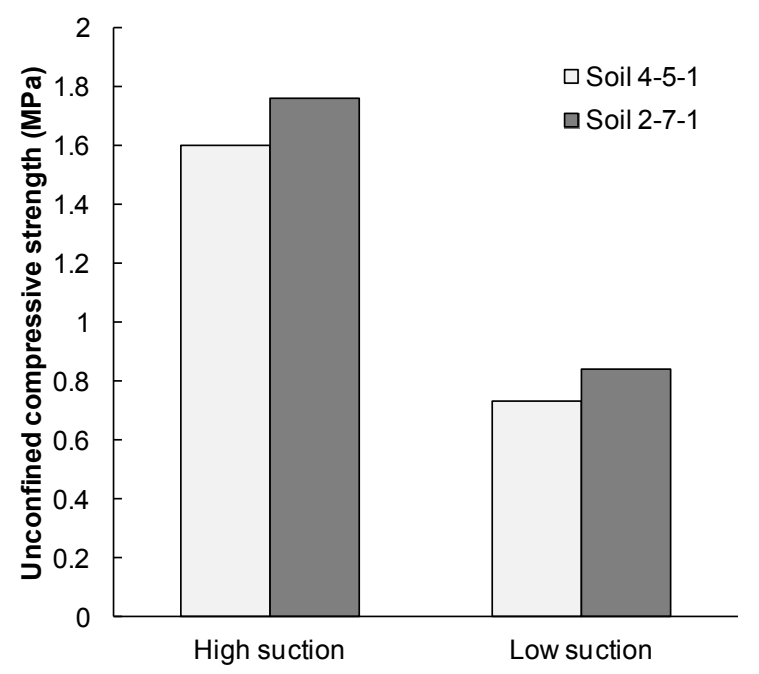

Figure 9: Soil 4-5-1 and 2-7-1 UCS under high and low equilibration suction conditions

construction standard) requires a minimum compressive strength of 1.3 MPa for a soil to be considered suitable for construction; if a proposed soil were tested under inappropriate conditions, it might either be rejected unnecessarily, increasing costs as alternative soils must be sourced, or approved inappropriately which could potentially lead to catastrophic failure. Such outcomes cannot be discovered using traditional testing or analysis methods, for example those based on concrete or

Table 1. Soil 4-5-1 and 2-7-1 material properties. MPT: Modified Proctor Test (BS1377); $\rho_{d_{\max }}$ : maximum dry density. Percentages and water contents by mass.

\begin{tabular}{llllll}
\hline Soil & $\begin{array}{l}\text { Silty } \\
\text { clay } \\
(\%)\end{array}$ & $\begin{array}{l}\text { Sand } \\
(\%)\end{array}$ & $\begin{array}{l}\text { Gravel } \\
(\%)\end{array}$ & $\begin{array}{l}\text { OWC } \\
(\%)\end{array}$ & $\begin{array}{l}\text { MPT } \\
\rho_{d_{\max }} \\
\left(\mathrm{kg} / \mathrm{m}^{3}\right)\end{array}$ \\
\hline $4-5-1$ & 40 & 50 & 10 & 12.0 & 1940 \\
$2-7-1$ & 20 & 70 & 10 & 12.0 & 1960 \\
\hline
\end{tabular}

masonry. For an industry based on risk minimisation, an appreciation of the implications of unsaturated soil behaviour is clearly a benefit.

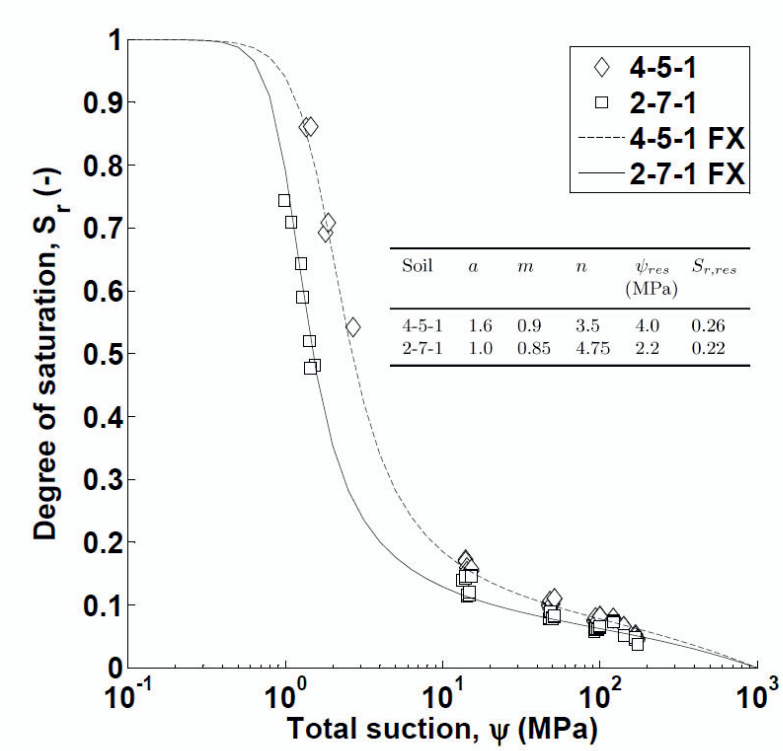

Figure 10: Soil water retention curves for soils 4-5-1 and 2-7-1 and approximations using the Fredlund and Xing [27] model (parameter values given in inset table).

\section{Conclusions}

This paper sets out the case for geotechnical engineers interested in unsaturated soil mechanics to consider applying their ideas to earthen construction materials. It identifies where existing work might be of use and also identifies some challenges where discussion and research is required. It is to be hoped that the paper will inspire younger researchers to take a look at these fascinating materials.

It seems clear that engineers need to find an approach which makes use of a range of test procedures from geotechnics and structures and combines this with unsaturated soil mechanics principles. A useful goal would be a EC mix design procedure similar to that used for concrete, which begins with the selection of a target compressive strength, a link to the water cement ratio to deliver that strength followed by inclusion of steps to ensure the right workability. It is a procedure that is robust, within the limit state framework it occupies, and a similar approach for EC materials could allow one to specify a manufactured unsaturated soil.

Finally, another area of potential interest linked to EC, and one perhaps closer to traditional geotechnical engineering, is the exploitation of suction as a source of strength in unsaturated soils; this is effectively what one is doing when creating EC materials and could be employed on lower suction situations such as mass retaining walls, foundations and, in particular, temporary works. In fact this is one part of a recently commenced EC-funded research network "Training Engineers and Researchers to Rethink geotechnical Engineering for a low carbon future" (TERRE) led by Strathclyde University [28]. 


\section{Acknowledgements}

The work described in this paper draws from experiences supervising the research projects of a number of $\mathrm{PhD}$ and MEng students at Durham over the past 5 years. The assistance provided by the Durham XRCT Facility, which was funded in part by the UK EPSRC (grants $\mathrm{EP} / \mathrm{K} 036084 / 1 \quad \& \quad \mathrm{EP} / \mathrm{K} 024698 / 1), \quad$ is gratefully acknowledged.

\section{References}

1. P.A. Jaquin, C.E. Augarde, Earth Building: History, Science \& Conservation, IHS BRE Press: Bracknell, (2012).

2. H. Houben, H. Guillard, Earth construction: a comprehensive guide. London: ITDG Publishing (1994).

3. P. Walker, R. Keable, J. Martin, V. Maniatidis, Rammed earth design and construction guidelines. Watford: BRE Bookshop, (2005).

4. D. Ciancio, C.T.S. Beckett, C.E. Augarde, P.A. Jaquin, ICE Proc. Constr. Mats, to appear (2016).

5. S. Lenci, F. Clementi, T. Sadowski, Eng. Frac. Mech. 87:62-72 (2012).

6. I. Lombillo, L. Villegas, E. Fodde, C. Thomas, Constr. Bldg Mats 51:451-460, (2014).

7. D. Gelard, L. Fontaine, S. Maximilien, C. Olagnon, J-P. Laurent, H. Houben, H. Van Damme, Proc. Int. Symp. Earth. Struct., Bangalore, 22-24 August (2007).

8. P.A. Jaquin, C.E. Augarde, D.G. Toll, D. Gallipoli, Géotechnique, 59(5):487-490 (2009).

9. P.A. Jaquin, C.E. Augarde, L. Legrand in Proc. $1^{s t}$ EUNSAT, Durham, UK, 417-422 (2008).

10. D. Gallipoli, A.W. Bruno, C. Perlot, N. Salmon, in Unsaturated Soils: Research and Applications, 5562 (2014).
11. H. Nowamooz, C. Chazallon Constr. Bldg Mats, 25:2112-2121 (2011).

12. P. Gerard. M. Mahdad, A.R. McCormack, B. Francois, Constr. Bldg Mats 95:437-447(2015).

13. C.T.S. Beckett, J.C. Smith, D. Ciancio, C.E. Augarde, Géotechnique Letters, 5:254-260, (2015).

14. E.E. Alonso, N.M. Pinyol, A. Gens, Géotechnique, 63(6):463-478 (2013).

15. A. Koliji, PhD Thesis, EPFL, Switzerland, (2008).

16. Brune, P.F., Ingraffea, A.R., Jackson, M.D. \& Perucchio, R. Eng. Frac. Mech., 102: 65-76, (2013).

17. A. Corbin, C.E. Augarde, Proc. Mat. Sci 3:1675 1680 (2014).

18. L. Miccoli, D.V. Oliveira, R.A. Silva, U. Müller, L. Schueremans, Mat. Struct., 48:3443-3456 (2015).

19. J.C. Smith, PhD Thesis, Durham University, (2015).

20. N.C. Consoli, L. Da Silva Lopes, L. Jr, B.S. Consoli, L. Festugato, Géotechnique 64:165-170 (2014).

21. V. Robin, A.A. Javadi, O. Cuisinier, F. Masrouri, Comp. Geotech, 66:189-202 (2015).

22. J.C. Smith, C.E. Augarde in Proc. First International Conference on Rammed Earth Construction (ICREC), 145-149, (2015).

23. S.M. Hejazi, M. Sheikhazdeh, S.M. Abtahi, A. Zadhoush, Constr. Bldg Mats 30:100-116 (2012).

24. D. Readle, S. Coghlan, J.C. Smith, A.J. Corbin, C.E. Augarde. ICE Proc. Constr. Mats, to appear (2016).

25. J.G. Zornberg, Géotechnique 52:593-604 (2002).

26. A. Diambra, E. Ibraim, Géotechnique, 65:296-308, (2015).

27. TERRE, http://cordis.europa.eu/project/rcn/198308 en.html

28. D.G. Fredlund, A. Xing, Can. Geo. J 31:521-532 (1994). 